\title{
Ecourbanistica: toward a new sustainable town planning
}

\author{
R. Fistola \\ Department of Engineering, University of Sannio, Italy
}

\begin{abstract}
A social conscience about what is going on in relation to climate changes, global warning, urban pollution, water emergencies, the municipal solid waste problem and, in general, future urban scenarios seem to be quite widespread in large segments of the population. The city, where in a few years about $75 \%$ of the world's population will settle, represents one of the main entropic systems, in particular because of the location of climate-altering and pollutant activities. This awareness has generated an ethic change, a radical transformation of the methods of action and interaction between man and the environment and between citizens and the urban environment. The attention to sustainable urban development, participated urban planning, the consideration of territory as a non renewable resource, sustainable mobility and so on has also been characterizing the investigation in the field of urban and regional sciences. Moving from these assumptions it is now necessary to codify a new process of sustainable town planning that is able to indicate the real actions necessary within the city. This paper intends to describe this new process, called Ecourbanistica (Ecotownplanning), starting from the systemic approach to the city.

Keywords: Ecourbanistica, Gaia hypothesis, complex system, new town planning, sustainable urban development, systemic approach, climate change, urban entropy, Mediterranean city, urban transformation management.
\end{abstract}

\section{Gaia and Polis}

Considering the earth as a living organism capable of self-regulation, through the constant search for balance among its several components, represents the basic intuition of the "Gaia hypothesis" worked out by James Lovelock in the 1960s. According to Lovelock's view, based on systemic logic and cybernetics, the 
living planet is able to reach balance by absorbing the entropic effects produced by the behaviour of some biological components (biocenosis), in some cases by neutralizing/eliminating those components. Every organism modifies its biotype (from bacteria to human beings) but the effects of this modification are then balanced by the cycles of the planet (Lovelock [1]).

In the course of the history of our planet all the events capable of producing epoch-making changes have been almost metabolized and included into the big cycle: order/chaos allowing one to reach new balances. Consequently the vital cycles of living bodies are functional to our planet's survival; for example, we should consider that the coral reefs are made up of the carcasses of sea organisms or that the biosphere is fed also by the methane produced by bacteria and decomposition of biological masses.

Gaia has always been living thanks to a dynamic harmony entailing birth and death. At present, a new condition seems to appear, which is characterized by an increasingly difficult achievement of balance; there are earth components whose capability of change produces effects that the planet is not able to compensate. The phenomenon appears and grows, following an exponential rule, particularly in recent decades. Many other components of the planet's organism seem to suffer and be incapable of participating in that dynamic search for harmony that for some billion years has characterized life on earth. Unfortunately, the cause of the unbalance should be unequivocally attributed only to one earth species: man. The theory of Anthropocene analytically describes the process of change produced by human activities (Crutzen [2]).

The climate changes, felt also at local level, are a socially appreciable sign of the undergoing global dyscrasia.

Gaia goes on by cycles: the chlorophyll photosynthesis, the cycle of oxygen, the geo-chemical cycle and the ocean streams; according to the alternation: cold/hot, order/chaos, and so on. The cycle of oxygen allowing life on earth shows worrying modifications. The increase of greenhouse gases, the main cause of temperature increase on the planet, is producing important unbalances in many relationship cycles of earth system. The ocean stream (the Gulf stream), but the Mediterranean ones too, which determine the global climate balance, are changing (in temperature, salinity and flow) and seas are no longer capable of absorbing the carbon dioxide for the survival cycle, because of the surface water heating (which hinder the mixing with deep water.

The human entropy (Rifkin [3]) is increasing and is pushing from the inside the global earth cycle by making a disconnection inside the harmonic motion which causes a change towards a spiral process, fig. 1 .

Human beings, thanks to scientific and technological progress, are now capable of extending their biological life on the planet, almost altering their cycle and making their ecological mark deeper and deeper.

Some experts interpret the development of not curable diseases and lethal virus (such as Cancer, AIDS and Ebola for instance) as the Gaia's utmost attempt at reducing the anthropic pressure that she is incapable of balancing again. Considering earth as a supermarket planet from which drawing resources and energies to feed anthropic biological cycles, with high anthropogenic effect, 

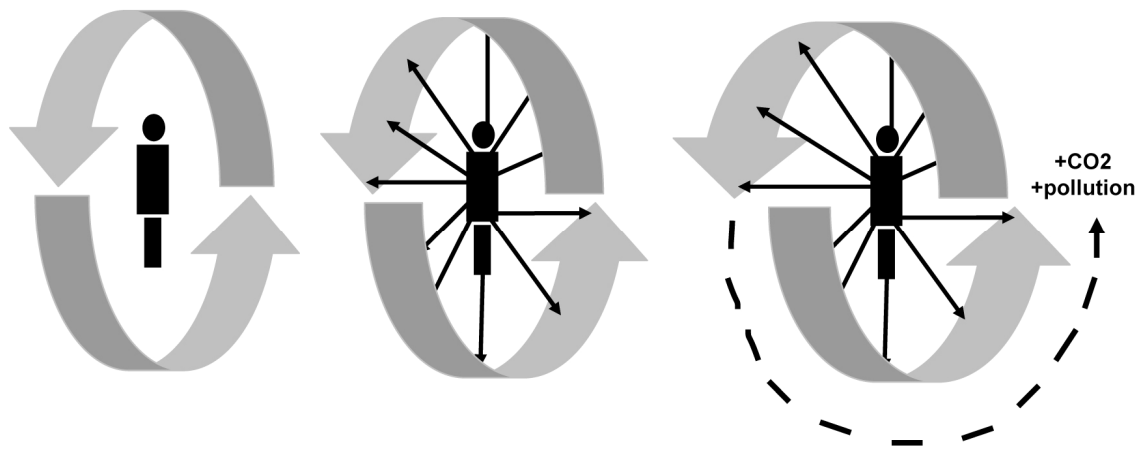

Figure 1: From cycle to spiral - human entropy pushing from inside the balanced cycle of Gaia makes a disconnection and changes the cycle in a dangerous spiral where pollution and carbon dioxide increase more and more.

has characterized human ethic of the last five centuries, a relatively short period for earth history, but tragically lethal for the planet. The quantity of entropy seems to be no more metabolized by Gaia or anyway does not allow one to reach a balance in a fast way as in the past.

Many of these assumptions belong to the ecologist approach that from Capra to Rifkin, from Batheson to Crutzen has been stigmatizing the self-injurer behaviour of earth inhabitants and in particular of those belonging to the west of the world. According to that approach, the environmental emergency and energy problem should be considered, since they are both entropic phenomena strictly correlated. The energetic mono-reference, linked to the use and exploitation of fossil fuel, represents a rigidity of the anthropic organization that is producing endogenous unbalances and could briefly determine worrying "flakings" in the global socio-economic organization.

Besides the problem is national and macro-regional and is still more serious for the European ambit and the Mediterranean and Italian ambit, in particular.

By analyzing the reports and studies of the IPCC and the Environment European Agency we can infer that, during the last century, in Europe a medium temperature increase of $0,95^{\circ}$ has been recorded with much relevance in winter.

The deglaciation has reduced about $50 \%$ of the volume of European glaciers since 1850 , in particular the alpine glaciers have lost about $70 \%$ of their volume, which will produce, around 2060, the disappearance of glaciers at the height of $3.500 \mathrm{mt}$. Indeed over one century, the precipitations have increased in the north Europe and decreased in the south; this trend will further go on in the following years. In the Mediterranean, as already said, there is a problem of change and remixing of water whose temperature is remarkably increasing. This fact is caused also by the reduced flow of rivers produced by anthropic yield and generally by the modification of streams. Those foolish and uncontrolled actions increase the "salt wedge" at the mouths because of the scarce yield of fresh water into the sea. The expectations on the increase of the sea level/year are contrasting and show a fork going from $\mathrm{mm}$. 1,8 to $\mathrm{mm} .8,0$. 
Italy can suffer the effects of global change from many points of view: in particular for the configuration of the land, especially exposed to hydrogeological risk improved by the high intense meteorological events, for Km. 8.000 of coast and about 38 coast territories at flood risk. Besides the combination between precipitation reduction and medium temperature increase will produce higher frequency of heat waves. In particular as to Italy, there will be a serious problem of water availability, estimated at 50 billion cubic meters each year at present, which will greatly lessen, increasing also the already existing gap between North and South and isles. The water stress will affect many activities sectors in the South, such as: agriculture, industrial production, tourism, residence, health, and so on. Besides there will be the phenomenon of Northern-shift of ecological systems mostly in South Italy, with consequent change of landscape and local fauna. In many territories, the fauna migration is, nevertheless, stopped by the splintering and blocking of ecological corridors made by urbanization and infrastructural works. In Italy, between 1990 and 2005 , the emissions of greenhouse gases increased by $12,1 \%$. If we analyze the percentage of carbon dioxide emission (leaving apart the other greenhouse gases) produced by the different anthropic activities, we find that the main contribution is given first by energy production, then by transport and finally by tertiary and residential activities (largely by home heating). And specifically these sectors should be the first targets of mitigation, which individuates the urban ambit as chosen site. The problem is particularly felt in urban areas.

The claim saying, "witnesses of climate", describes the perception of undergoing transformations popularly diffused by now. As refers to the climate change, cities are affected by high rate of pollution by hydrocarbon, high urban temperature (heat islands), limited and extremely intense meteorological phenomena (water bombs), appearance of alien species, acid rain, manifestation of new respiratory and allergic pathologies (the rise of one temperature degree seems to provoke an increase by $3 \%$ of urban death-rate), and so on. A specific consideration should be done for the analysis of the impacts on national economy, whose main pulling sectors (industrial production, tourism, agriculture, services, and so on) are strongly affected by climate changes and water availability.

Summing up, it is clear that it is necessary to activate knowledge and competences in all activities fields, but with first reference to scientific research in order to work out and implement as soon as possible the actions of mitigation and strategies for adapting to the ongoing global changes. Italy is among the more exposed and vulnerable nations. All the other Countries look at our Country as possible example to follow in order to find the harmony between man and earth.

A city represents the place of maximum anthropic concentration and can be conceived as a dissipative structure, Prigogine and Stengers [4]. The approach to the city as a complex dynamic system has to be mixed with the entropy concept.

In view of mitigation, urban systems should be considered as systems with high "anthropic entropy". Urban systems represent the place where interventions are needed and can be carried out in quite a short time. The procedures, 
protocols, rules, practices for the new governance of territorial transformations should necessarily start from the negentropic intervention on the functional system (residence, mobility, production, services, and so on) and on physical system (urban layout, heliothermic orientation, tones of surfaces and covers increasing the albedo, home microgeneration systems) of the city. The approach and the indications for the intervention can refer to a new way of considering the governance of territorial transformations being based on sustainability, climate and energetic emergency.

Ecotownplanning, starting from the assumption that territory is a nonrenewable resource, suggests indications both for mitigating and adapting to urban climate change and represents an attempt to systematize the intervention on urban system components.

\section{A lesson from the past}

The captation of natural energies, collection and domestic use of rain-water, the orientation of houses according to the heliothermic axis to foster heating and insulation, use of arboreal essences for shade and inhabitants protection and many other "rules" which have been characterizing the human settlement for ages, and in particular the layout of Mediterranean city, have been got rid of with the advancement of technology, starting from the industrial revolution.

Before the Second World War there were very few buildings using the central heating plant with boilers which warmed water and piped it in the radiators of the houses. It is worth mentioning too that already in 1891 the American Clearence Kemp patented the first solar thermic plant and in 1897 one third of the houses in Pasadena, in California, were equipped with solar equipment for water heating.

The use of heating technologies seemed to free cities and architectural works from the bonds of heliothermic exposure, which from the first examples of collective change and adaptation of anthropic environment for developing a residential function - the city of UR in Mesopotamia, for example - characterized the building rules. The Mediterranean city still preserves characteristic houses which could be summed up according some basic principles:

- Chess-wise urban pattern to foster aeolian passage and air change

- Orientation according to the heliothermic axis

- Use of local building materials

- White or light painting of outside walls and of several traces to reflect solar radiation

- Court typologies to help cooling

- Systems of rain-water collection

- Use of specific techniques for inside ventilation and climatization

- Location of fountains to lower urban temperature

We could quote other indications, but the listed ones seem to be the most characterizing. In particular, as regards urban structure, the examples of chesswise cities are several and go from Greece of Hippodamus to Barcelona of Ildefonso Cerdà. The typologies with inner court characterize the historical 
nuclei of many Arab and African cities, typically painted with white lime like many other historical centres in South Italy. An interesting example of old techniques of house ventilation are the wind tower characterizing Iran and Pakistan, which caught fresh air at a certain height and introduced it into the rooms in order to produce a natural air recycling and cooling inside them The baud geers have been recently used in some buildings of Morocco.

All the indications above said belong to the Ecotownplanning indications and are interpreted again to reshape the urban physical system.

\section{Toward a new way of managing urban transformation: the Ecotownplanning (Ecourbanistica)}

The systemic approach applied to the city moves from the General System Theory (von Bertalanffy [5]) and takes into account that it is one of the main references for the Ecotownplanning. Furthermore it is possible to find also a strong reference to the new vision of the city: "as a complex self-adapting system, or even a living ecosystem", Pulselli et al. [6]. Here we aim at suggesting a systemic approach to the climate change problem in urban context, which entails the analysis of the different subsystems and the study of its components and relationships as regards global warming. The generally proposed actions refer to single useful but insufficient interventions. The unbalance refers to a systemic layout and so it is necessary to systematically work in order to recover the balance. The interventions should issue from this approach towards a sustainable urban planning. Consequently we could state that Ecotownplanning takes its approach from the systemic theory of city and aims at recovering an endosystemic balance by stopping the production of entropy inside the different subsystems (physical, functional, socio-anthropic, geo-morphologic, psycho-perceptive, and so on) and the production of negentropy thanks to the start of energetic interactions between the different subsystems, Fistola [7]. For instance, the availability of an efficient waste cycle allows to produce energy useful to the functional system, avoids the amassing of litter (which could cause a sanitary problem to the socio-anthropic system).

Among many system properties, we can detect one particularly interesting for our study: each system it's included in a bigger system (meta-system) and its parts are under systems (sub-systems). It is possible to affirm that among the different sub-systems forming the urban system we can detect three of them: a functional system, a physical system and a socio-anthropic system, fig. 2.

This conceptual distinction does not find any confirmation in physical reality, where the mentioned systems are indivisible, but abstraction is permitted due to the adoption of the systemic logic for building up the interpretative framework. The functional system consists of all urban activities (functions) and of relation among those (communications).

The physical system consists of all urban spaces (houses, streets, and squares) inside which activities take over and networks where (physic, energetic, telecommunication, etc.) communications flow. 


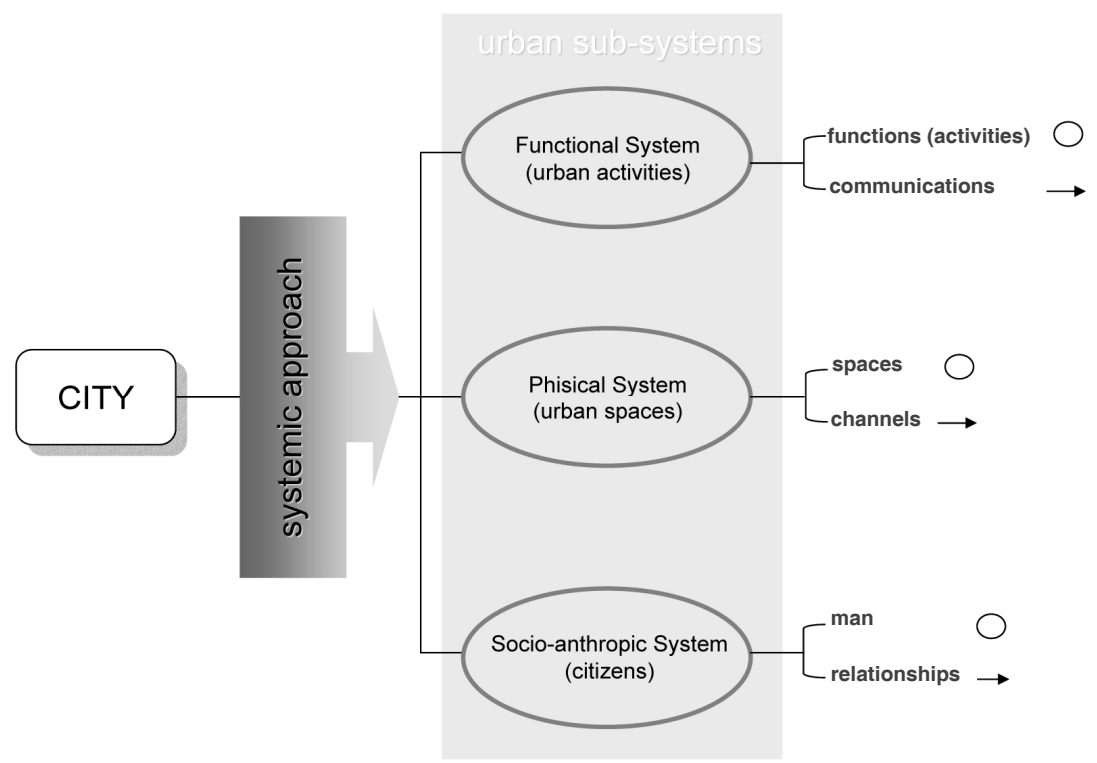

Figure 2: The urban system and the three sub-systems detected in the systemic approach.

The socio-anthropic system is composed by the urban community: the citizens (urban actors, stakeholders, decision makers and so on) and relationships among them.

The three sub-systems compose the urban one and are linked by relations which allow one to connect to each element of the functional system the same in the physical system where activity takes place developed by citizens, Fistola [8].

Ecotownplanning is naturally rooted in: Gaia hypotesis, complexity theory which represents the contemporary embodiment of general system theory, Batty [9] - urban ecology, in the theory of entropy and "anthropocene", in bioarchitecture, in the definition of sustainable city, in the assumption (being apparently revolutionary but expressed already in the first '80) that the city should be considered as a natural ecosystem, Grieco 1981) and as such should be rebalanced with the same earth ecosystems.

Ecotownplanning, moving from a systemic approach, shows the real actions to implement in order to manage urban transformation targeted to reduce anthropic entropy. The whole process, considering again the classic phases of urban transformation governance (knowledge, decision and action), could be articulated in the following phases:

Knowledge phase

- Systemic interpretation of the city

- Reading, measure and analysis of urban entropy

- Multilevel interpretation of urban condition 
- Listening to the instances and proposals of urban stakeholders, actors and citizens

Decision phase

- Definition of reachable targets

- Sharing the targets with the urban actors

- Setting up policies for sustainable governance of urban transformations

- Transformation of policies into urban plan actions

- Communication and diffusion of urban plan choices

Action phase

- Definition of regulations to implement urban plan actions

- Applying management and support initiatives to implement urban plan actions

As regards the first phase some studies should be worked out in order to show the conditions of the city different parts. By using the Geographic Information System (GIS) it's possible to work out an information model of territory structured according to levels that can be populated through geo-referenced data on city. Interesting initiatives to collect and systematize the data on the environmental quality of urban and metropolitan areas are being realized by the Italian Agency for Environment Protection and Technical Services, which draws up a yearly report on the topic and arranges and updates useful on-line sites, APAT [11]. The Urban Information Model enables to obtain and show the different pieces of information about anthropic/entropy phenomena. So it will be possible to work out several knowledge bases (digital maps) regarding the presence and entity of the processes.

We can roughly foreshadow the following information bases:

- Map of urbanized surfaces according to building material and typology

- Map of the destinations of use showing the use intensity

- Map of the intensity of vehicles flows on cinematic network

- Energetic Map (energy consumption of the activities on the territory)

- Map of heat isles

- Map of urban micro-climate

- Map of air quality

- Map of green presence

- Map of soil consumption

- Map of urban solid waste production

- Map of soil permeability

- Map of urban albedo

Starting from the collected information, its analysis and shared systematization of the targets, differentiating the "ethics" according to the different urban subsystems, the following action can be anticipated: 
Functional System

- Planning multifunctional urban zones

- $\quad$ Abating the excessive intensity of use also by adopting new information technologies capabilities

- Requalification of urban contexts by pointing out and recovering the original morphologies and chromatisms

- Safeguard of the remaining green spaces and project of new areas destined to urban green with appropriate study of shadows

- Paying particular attention to project and treat the surfaces of urban voids

- Making the vacant sites functional again by giving preference to green destinations or by creating new structures for energy production from alternative sources (solar plants, wind parks, and so on)

- $\quad$ Supporting the processes of urban identity sense of belonging

- $\quad$ Safeguarding the memory of sites

- Tending to the recovery of city's semantic values

- Arranging forms of sustainable urban mobility (discouraging private vehicle transfers and fostering the public transport and mobility cycle)

- Mobility through car sharing, car pulling, and so on

- Organizing interchange car parks outside the urban agglomeration and not placing multi-storey car parks in the centre on near it

- $\quad$ Promoting the recycle and integrated management of waste

- Using alternative sources for the energy needs of city (photovoltaic, solar, thermic, solar thermodynamic, aeolian, biomass, and so on).

Physical System

- In the new planning the exposure should be considered according to the heliothermic axis and the predominant winds

- Safeguarding the ecologic network and green areas

- $\quad$ Providing for protected and wooded pedestrian routes (green corridors)

- Providing for an interconnected network of urban green areas articulated into spaces and corridors

- $\quad$ Providing for cycle network for urban crossing

- Promoting bio-architecture

- Providing for rain water collection, recycle and phytopurification

- Taking into consideration high energetic efficiency (insulation)

- Supporting the energetic micro-generation and diffused generation

- $\quad$ Preferring the use of local materials

- Using green roofs for buildings

- Preferring the use of natural and/or recycled materials

- Providing for the use of outside photofixing paintings for $\mathrm{CO} 2$ and $\mathrm{CO}$

- Use of fountains and water vaporizers to abate temperatures and impeding the heat islands

- Use of molecular dissociators for urban solid waste treatment 
- Planning the carbon sequestration plant near carbon or industrial plants that cannot be replaced

- Use of light materials and chromatisms to increase the earth albedo

- Increasing the surfaces destined to public green areas (for air filtering from dust, abatement of temperature and $\mathrm{CO} 2$ )

\section{Law and Management Interventions}

- Working out appropriate building regulations and implementing technical laws inspired to mitigation and adaptation to climate change

- Providing for system of municipal certification of the energetic efficiency of buildings

- $\quad$ Spreading the social culture of recycle and supporting the differentiated waste collection

- $\quad$ Fostering the birth of the Energy Service Companies (ESCO) in order to spread the microgeneration and energy independence of buildings

- Discouraging the penetration mobility in the urban centre (road pricing, congestion charge, and so on).

\section{Conclusions}

The urgent need for new procedures, actions and, maybe, methodologies to face urban climatic change is felt by every urban operator. In Italy many institutions and organizations are implementing networks and producing interesting studies. All over the world the experts share ideas and tests in order to intervene in the city. It is now necessary to radically change the models of behaviour and use of resources and, probably, to redefine the model of economic development too.

A new town planning is required, which would reorganize its protocols through a systemic approach to the city, basing on sustainability, organizing through participation and developing through action of urban mitigation and adaptation.

The first implementable action of mitigation concerns the models of individual behaviour in relation to saving, recycle and reuse. Each person should be aware that there is need for a new social ethic made of little daily gestures.

Sustainability should become a value diffused through the practices of participated town planning. It is essential to foster new bottom-up initiatives that can rightly enter the Ecotownplanning process. Instead of discussing and analyzing the possible connotations of sustainability and interaction of the Italian town planning tools, whose matrix refers to 60 years ago, when the environmental and ecological theories were considered irritating assumptions of visionaries against urban development, it would be better to conceive a sort of town planning refounding in the Country, taking also in consideration the "legislative fluctuation" of the so-waited-for law on territorial governance. The Ecotownplanning should represent a first proposal of method, procedures and laws which propose a new sustainable development of city capable of governing the future urban transformation. It does not mean to choose the zero opinion 
stopping any activity and change, but to join development with the policies of sustainability, compatibility, solidarity and inclusive modernization.

Polis and Gaia should come back, or at least tend, to a new systemic balance, but acting in a fast way.

The experts, regional scientists, town planners and operators for managing urban and territorial transformations should answer the new present questions on urban future. We should hurry to recover a global balance (even if non perfect) and assure a satisfying urban quality also to the future generations whose survival will depend on our present choices.

\section{References}

[1] Lovelock, J., A new look at life on earth, Oxford University Press: New York, 1979.

[2] Crutzen, P., Benvenuti nell'Antropocene. L'uomo ha cambiato il clima, la terra entra in una nuova era, Mondadori: Milano, 2005.

[3] Rifkin, J., Entropy: Into the Greenhouse World, Bentam, Rev Rei edition, 1989.

[4] Prigogine, I. \& Stengers, I., La Nouvelle Alliance, Gallimard, Paris, 1979.

[5] von Bertalanffy, L., General System Theory, Penguin Books, Harmondsworth, 1972.

[6] Pulselli, R.M., Ratti, C., Tiezzi, E., City out of caos: social patterns and organization in urban systems. International Journal of Ecodynamics, Vol. 1, No. 2, pp. 125-134, 2006.

[7] Fistola, R., M.E-tropolis- funzioni innovazioni trasformazioni della città, I.Pi.G.E.T. CNR - Giannini, Napoli, pp. 24-27, 2001.

[8] Fistola, R., La città come sistema, (Volume II, Chapter 2). Per il XXI secolo una enciclopedia. Città cablata e nuova architettura, eds. C. Beguinot and U. Cardarelli, Università degli Studi di Napoli "Federico II" (Di.Pi.S.T.), Consiglio Nazionale delle Ricerche (I.Pi.Ge.T.), Napoli, 1992.

[9] Batty, M., Less is more, more is different: complexity, morphology, cities, and emergence. Environmental and Planning B: Planning and Design, 27(2), 2000.

[10] Grieco, G., Città per vivere, intervista sull'ecologia urbana, Società Editrice Napoletana, Napoli, 1982.

[11] Italian Agency for Environment Protection (APAT): Sistema nazionale per la raccolta, l'elaborazione e la diffusione di dati Climatologici di Interesse Ambientale (SCIA). www.scia.sinanet.apat.it 